\title{
ERRATUM
}

\section{Selective transmission of CCR5-utilizing HIV-1: the 'gatekeeper' problem resolved?}

\section{Leonid Margolis and Robin Shattock}

Nature Reviews Microbiology 4, 312-317 (2006), doi: 10.1038/nrmicro 1387

In the above article, references 51-54 were absent from the reference list. These references are listed below. We wish to apologize to the authors, and to readers, for any confusion caused.

51. Reece, J. C. et al. HIV-1 selection by epidermal dendritic cells during transmission across human skin. J. Exp. Med. 187, 1623-1631 (1998).

52. Smith, P. D., Meng, G., Salazar-Gonzalez, J. F. \& Shaw, G. M. Macrophage HIV-1 infection and the gastrointestinal tract reservoir. J. Leukoc. Biol. 74, 642-649 (2003).

53. Mattapallil, J. J. et al. Massive infection and loss of memory CD4+ $\mathrm{T}$ cells in multiple tissues during acute SIV infection. Nature 434, 1093-1097 (2005).

54. Vicenzi, E. et al. Envelope-dependent restriction of human immunodeficiency virus type 1 spreading in CD4 ${ }^{+}$ T lymphocytes: R5 but not X4 viruses replicate in the absence of T-cell receptor restimulation. J. Virol. 73, 7515-7523 (1999). 